\title{
Relationship between Dyspnea in Daily Life and Psycho-physiologic State in Patients with Chronic Obstructive Pulmonary Disease during Long-Term Domiciliary Oxygen Therapy
}

\author{
Michiaki Mishima, Yoshitaka OKu, Shigeo Muro, Toyohiro Hirai, Kazuo Chin, Motoharu Ohi, \\ Masakiyo NaKagawa ${ }^{1}$, Masanori Fujita ${ }^{2}$, Kimihiko $\mathrm{SAto}^{3}$, Kazue Shimada ${ }^{4}$, \\ Shinpachi YamaokA ${ }^{5}$, Yoshiro Oda ${ }^{6}$, Nobuaki $\mathrm{AsaI}^{7}$, Yanosuke SAGAWA ${ }^{8}$ and Kenshi Kuno
}

We examined the relationships among dyspnea ratings in daily life, the physiologic state, and anxiety and depression of fifty-two patients with chronic obstructive disease (COPD) during longterm domiciliary oxygen therapy (LTOT). Clinical ratings of dyspnea were assessed by the visualanalog scale (VAS) during eight types of basic behavior in indoor daily life. Analysis of the physiologic state included forced expiratory volume in 1 second $\left(\mathrm{FEV}_{1.0}\right)$, and arterial blood gas $\left(\mathrm{PaO}_{2}, \mathrm{PaCO}_{2}\right)$ at rest while breathing room air. The hospital anxiety and depression (HAD) scale, which consists of 14 questions, was used to assess the degree of anxiety (HAD-A) and depression (HAD-D). The mean age of the patients was 69.5 \pm 10.8 year (SD), and the duration of LTOT was 944 \pm 739 days. The mean values were $0.77 \pm 0.45 \mathrm{~L}$ for $\mathrm{FEV}_{1.0}, 57.7 \pm 7.4$ Torr for $\mathrm{PaO}_{2}$, and $47.4 \pm 8.1$ Torr for $\mathrm{PaCO}_{2} . \mathrm{FEV}_{1.0}$ was correlated with $\mathrm{PaCO}_{2}(\mathrm{r}=-0.548, \mathrm{p}<0.0001)$, but it was not correlated with $\mathrm{PaO}_{2}$. High correlation was noted between $\mathrm{HAD}-\mathrm{A}$ and $\mathrm{HAD}-\mathrm{D}(\mathrm{r}=0.693, \mathrm{p}<0.0001)$, whereas correlation was not noted between $\mathrm{HAD}$ and the physiologic state. VAS was significantly correlated with FEV 1.0 $(r=0.320, p<0.05)$, as well as with HAD-A $(r=0.358, p<0.01)$ and HAD-D $(r=0.444$, $\mathbf{p}<\mathbf{0 . 0 1}$ ). Dyspnea ratings were found to be influenced by anxiety and the depression state, and also by the degree of flow limitation in patients with COPD during LTOT. In contrast, the physiologic state scarcely influenced the anxiety and depression state. Thus, psychotherapy may play an important role in the reduction of dyspnea sensation, which is an important determinant of quality of life.

(Internal Medicine 35: 453-458, 1996)

Key words: long-term domiciliary oxygen therapy (LTOT), depression, anxiety, visual-analog scale (VAS), forced expiratory volume in 1 second $\left(\mathrm{FEV}_{1.0}\right)$

\section{Introduction}

Dyspnea is a common complaint of patients with chronic pulmonary obstructive disease (COPD) and an important determinant of their quality of life (1-3). It has been recognized that the intensity of dyspnea for a given degree of functional impairment is variable among COPD patients (4). One of the factors that causes disproportionately severe breathlessness in
COPD is psychiatric illness (5). Indeed, COPD patients often suffer not only from functional but also from psychiatric disorders resulting in diminished activity in personal and social life (6). Namely, COPD patients during long-term domiciliary oxygen therapy (LTOT) are compelled to restrict their daily life mainly to indoor activities, and the history of repeated deterioration of their illness makes such patients concerned about death. These stressful conditions may worsen mood distur-

From the Department of Clinical Physiology, Chest Disease Research Institute, Kyoto University, Kyoto, 'Tsukaguchi Hyogo Prefectural Hospital, Hyogo,

${ }^{2}$ Kitano Hospital, Osaka, ${ }^{3}$ Ohtu Red Cross Hospital, Shiga, ${ }^{4}$ Shiga Medical Center, Shiga, ${ }^{5}$ Saiseikai Noe Hospital, Osaka, ${ }^{6}$ Osaka Red Cross Hospital,

Osaka, ${ }^{7}$ Asai Clinic, Hyogo and ${ }^{8}$ Toyosato Hospital, Shiga

Received for publication August 23, 1995; Accepted for publication April 2, 1996

Reprint requests should be addressed to Dr. Michiaki Mishima, the Department of Clinical Physiology, Chest Disease Research Institute, Kyoto University, Shogoin Kawahara-cho 53, Sakyo-ku, Kyoto 606 
bances such as anxiety or depression (7). Thus, in the health care of COPD patients during LTOT, it is important to assess to what extent mood disturbances and dyspnea are interrelated under the influence of functional impairment.

Little is known about the relationship between dyspnea and mood disturbance in COPD patients during LTOT, since the quantitative assessment of the degree of dyspnea has been difficult in patients with very severe pulmonary disease. Conventional clinical techniques for rating dyspnea, such as the Medical Research Council (MRC) scale (8), the Baseline and Transition Dyspnea Indices (BTDI) (2), and Oxygen Cost Diagram (OCD) (9) are difficult to apply because the criteria for rating dyspnea are mainly related to outdoor activity and are not applicable to the typical life pattern of patients during LTOT. In addition, these criteria are designed to evaluate exercise capability by determining the threshold which evokes breathlessness. Therefore these techniques do not assess the degree of dyspneic sensations during baseline indoor activity.

Problems also exist in the estimation of anxiety or depression. Many types of questionnaires have been developed for the assessment of mood disturbance such as the Minnesota Multiphasic Personality Inventory (MMPI) (10), the Sickness Impact Profile (SIP) (11), the Trait Anxiety Inventory (TAI) (12) and the Beck Depression Inventory (BDI) (13). However, these questionnaires are not free from the influence of physiologic disturbances because they were developed under the assumption that the subjects are physically healthy. For example, sleep disturbance, anorexia and body weight loss are symptoms commonly found in patients with depression, but they are also recognized in many physical diseases including COPD. Thus, the degree of depression or anxiety could be overestimated if these questionnaires are applied to patients with COPD during LTOT.

In the present study, we designed a protocol to overcome these problems. The visual analog scale (VAS) was applied to assess the intensity of sensations of dyspnea during 8 basic indoor behaviors in order to quantify dyspnea in daily life. Mood disturbance was evaluated using the Hospital Anxiety and Depression (HAD) scale, which is designed to be free from the influence of the physical state (14). Our aim was to address to what degree sensations of dyspnea are affected by functional impairment and mood disturbances.

\section{Materials and Methods}

\section{Subjects}

Subjects consisted of 52 COPD patients (males: 43 , females: 9) during LTOT using oxygen concentrators, who were from the outpatient pulmonary disease clinics at the Chest Disease Research Institute Hospital and 9 city hospitals. Qualification criteria for LTOT were the following: arterial oxygen tension $\left(\mathrm{PaO}_{2}\right)<55$ Torr or $\mathrm{PaO}_{2}<56-69$ Torr if accompanied by ventricular hypertrophy revealed by electrocardiography (15) and/or pulmonary hypertension detected by right heart catheterization or by radiological signs (16). The mean \pm SD age was $69.5 \pm 10.8$ year, and the duration of LTOT was $944 \pm 739$ days. All patients were in a stable condition for at least one month before the examination.

\section{Psychological state testing}

We adopted a modified form of the HAD scale which was developed by Zigmond and Snaith (14). This scale has been translated into Japanese and published by Kitamura (17) under permission of the original author. It was re-translated into English by a person who did not know the original questionnaire, and the re-translation was confirmed by the authors to be appropriate. The HAD scale consists of 14 questions, with estimators for depression and anxiety arranged one after another. Great care was taken to ensure that the questions would not be influenced by the physical state of the subject. Full marks on both the anxiety (HAD-A) and the depression (HAD-D) scores were 21 .

\section{Dyspnea sensation testing}

VAS has been used by several investigators [Chonan et al (18) and Adams et al (19)] to quantify the intensity of dyspnea. On the first page of the VAS handed to subjects, the definition of dyspnea is documented as follows: "Dyspnea includes all types of uncomfortable sensations associated with breathing such as breathlessness and the sensation when one cannot breathe sufficiently. Any discomfort that does not relate to breathing, e.g., headache, nausea or languidness is not included". On the second page, 8 basic activities in indoor daily life from awakening to going to sleep (at rest, brushing, getting dressed, eating, going to the washroom, going up stairs, taking a bath, going to sleep) were listed on the left side of the page. On the right side of each category, closed bars $100 \mathrm{~mm}$ in length representing a VAS for dyspnea sensation were arranged. The Japanese sentences meaning "none at all" and "the most intense imaginable" were placed at the left and right ends of the bar, respectively. The patients were asked to place a line across each bar at the position they judged to be appropriate for expressing their dyspnea sensation during each activity. The intensity of sensations of dyspnea was defined as the distance in $\mathrm{mm}$ from the left end of the bar. The final score was expressed as the average VAS score for 8 bars, with the full mark being 100 .

\section{Experimental protocol}

While sitting on a chair, the examiner explained the purpose of the study to the patients. They were assured that the personal data would never be disclosed, and that a decision not to participate would not put them at a disadvantage. After informed consent was given, the examiner explained to the patients in detail the method by which to respond to the questionnaire, taking care that this information would not distort the results. After these procedures, the patients were left alone and answered the HAD scale and dyspnea sensation questionnaire in 30 minutes. The patients were requested to answer by reviewing the average psychological state and dyspnea sensation during the week before the examination date. When this procedure was finished, the examiner checked the sheets to make sure that the patients answered all the questions in the 


\section{Dyspnea and Psycho-physiologic State in COPD during Oxygen Therapy}

correct manner. Then, the arterial blood gas was sampled through a radial artery. The forced expiratory maneuver was then performed for the measurement of forced expiratory volume in 1 second $\left(\mathrm{FEV}_{1.0}\right)$. This maneuver was usually repeated 3 times, and the largest $\mathrm{FEV}_{1.0}$ was recorded. However, when the patients complained of suffering, the maneuver was not repeated. All these procedures were performed in the oxygen-off condition. This study was performed from October to November 1994, which is the most comfortable season in Japan, to avoid the influence of hot or cold weather on the psychologic or physiological state of the patients.

\section{Statistical analysis}

Correlation coefficients and significance between $\mathrm{FEV}_{1.0}$, $\mathrm{PaO}_{2}, \mathrm{PaCO}_{2}$, anxiety and depression scale (HAD-A, HAD-D and VAS score were estimated using the paired Student-t test.

\section{Results}

Regarding the physiologic state, a remarkable decrease of $\mathrm{FEV}_{1.0}(0.77 \pm 0.45 l$, mean $\pm \mathrm{SD})$, and hypoxic hypercapnia $\left(\mathrm{PaO}_{2}\right.$ : 57.7 \pm 7.4 Torr, $\mathrm{PaCO}_{2}: 47.4 \pm 8.1$ Torr $)$ were noted. HAD-A and HAD-D were 5.73 \pm 4.05 and 6.75 \pm 4.57 , respectively and no statistical difference was noted between the 2 parameters. Seven $(13.5 \%)$ and ten $(19.2 \%)$ patients were judged to be definite cases of anxiety and depression (HAD scale: $>10$ marks); nine (17.3\%) and eight (15.4\%) were judged to be cases of possible anxiety and depression (HAD scale: 810 marks), respectively. Thus 30.8 and $34.6 \%$ were under conditions of anxiety or depression to some degree. VAS was $35.5 \pm 19.1$, and minimum and maximum scores were 0.4 and 80.3 , respectively.

The correlations between these parameters are shown in the Table. For easy interpretation, the same correlation coefficients and $\mathrm{p}$-values are arranged on both sides of the diagonal line. Among the parameters of the physiologic state, $\mathrm{FEV}_{1.0}$ corre- lated remarkably with $\mathrm{PaCO}_{2}(\mathrm{r}=-0.548, \mathrm{p}<0.0001)$, while it did not correlate with $\mathrm{PaO}_{2}$. Significant correlation was noted between $\mathrm{PaO}_{2}$ and $\mathrm{PaCO}_{2}(\mathrm{r}=-0.326, \mathrm{p}<0.05)$. Among the parameters of the psychologic state, a high correlation was noted between HAD-A and HAD-D $(r=0.693$, $p<0.0001)$. However, no correlation was noted between the physiologic state and HAD. VAS correlated significantly with $\mathrm{FEV}_{1.0}(\mathrm{r}=0.320$, $\mathrm{p}<0.05)$ and also correlated significantly both with HAD-A $(\mathrm{r}=0.358, \mathrm{p}<0.01)$ and HAD-D $(\mathrm{r}=0.444, \mathrm{p}<0.01)$.

\section{Discussion}

There were reasons why all the procedures were performed in the oxygen-off condition. First, the aim for physical state testing was to address the basic condition of the patients. The deterioration of the basic ability of the oxygen uptake of the lung may be masked by the oxygen inhalation. We surveyed the blood gas analysis at rest during oxygen inhalation within one month before the examination, in 28 patients. The results of no correlation between $\mathrm{PaO}_{2}$ and $\mathrm{FEV}_{1.0}(\mathrm{r}=-0.012)$ and a significant correlation between $\mathrm{PaCO}_{2}$ and $\mathrm{FEV}_{1.0}(\mathrm{r}=-0.572, \mathrm{p}<0.01)$ were the same as those under the condition without oxygen inhalation. Similarly, no significant correlation was noted between blood gas and the results of psychological and dyspnea testing. However, the significant correlation between $\mathrm{PaO}_{2}$ and $\mathrm{PaCO}_{2}$ disappeared $(\mathrm{p}=-0.214)$. Second, the dyspnea rating in the present study was based on the review of dyspnea sensation during many types of the daily activities, and it may be better to avoid the condition at rest during oxygen inhalation when they answer the questionnaire because it is one of the daily activities included in the questionnaire. To estimate the influence of oxygen inhalation during the examination on the results, eight patients were randomly selected. The examination was performed with and without oxygen inhalation with an interval of one week, where the order was with oxygen and without oxygen in four patients and the opposite in the other four patients.

Table Correlation between the Parameters

\begin{tabular}{ccccccc}
\hline & $\mathrm{FEV}_{1.0}$ & $\mathrm{PaO}_{2}$ & $\mathrm{PaCO}_{2}$ & $\mathrm{HAD}-\mathrm{A}$ & $\mathrm{HAD}-\mathrm{D}$ & $\mathrm{VAS}$ \\
\hline $\mathrm{FEV}_{1.0}$ & & 0.003 & $-0.548^{* * *}$ & -0.081 & -0.268 & $-0.320^{*}$ \\
& & $(0.9817)$ & $(<0.0001)$ & $(0.5681)$ & $(0.0542)$ & $(0.0201)$ \\
$\mathrm{PaO}_{2}$ & 0.003 & & $-0.326^{*}$ & -0.179 & -0.055 & -0.221 \\
& $(0.9817)$ & & $(0.0177)$ & $(0.2055)$ & $(0.7006)$ & $(0.1153)$ \\
$\mathrm{PaCO}_{2}$ & $-0.548^{* * *}$ & $-0.326^{*}$ & & 0.196 & 0.212 & -0.009 \\
& $(<0.0001)$ & $(0.0177)$ & & $(0.1647)$ & $(0.1313)$ & $(0.9480)$ \\
$\mathrm{HAD}-\mathrm{A}$ & -0.081 & -0.179 & 0.196 & & $0.693^{* * *}$ & $0.358^{* *}$ \\
& $(0.5681)$ & $(0.2055)$ & $(0.1647)$ & & $(<0.0001)$ & $(0.0088)$ \\
$\mathrm{HAD}-\mathrm{D}$ & -0.268 & 0.212 & 0.212 & $0.693 * * *$ & & $0.444 * *$ \\
& $(0.0542)$ & $(0.1313)$ & $(0.1313)$ & $(<0.0001)$ & & $(0.0008)$ \\
$\mathrm{VAS}$ & $-0.320^{*}$ & -0.009 & -0.009 & $0.358^{* *}$ & $0.444 * *$ & \\
& $(0.0201)$ & $(0.9480)$ & $(0.9480)$ & $(0.0088)$ & $(0.0008)$ & \\
\hline
\end{tabular}

Correlation coefficients and p-values (in parenthis). (*: $\mathrm{p}<0.05, * *: \mathrm{p}<0.01, * * *$ : $\mathrm{p}<0.0001$ ). HAD-A, HAD-D, and VAS indicates Anxiety and Depression on HAD score, and visual analog score of dyspnea. 
FEV $_{10}$, HAD-A, HAD-D, and VAS in the conditions with and without oxygen were $0.68 \pm 0.33 l$ and $0.70 \pm 0.37 l, 5.10 \pm 3.84$ and $5.28 \pm 4.56,6.18 \pm 5.14$ and $6.06 \pm 5.03$, and $30.4 \pm 20.6$ and $28.9 \pm 17.4$. No significant differences were noted in any of these parameters (paired Student's t-test). The percent difference ratio between the values with and without oxygen [ $=100$ (withwithout $/$ /without] were $2.8 \pm 3.5 \%, 1.1 \pm 3.1 \%,-3.9 \pm 4.1 \%$ and $2.4 \pm 3.3 \%$, respectively. These results suggest that the influence of room air inhalation on the results of these parameters need not be considered in the present study.

The present study shows that the incidence of depression is high among COPD patients during LTOT. The result was similar to that reported by McSweeny et al (20), Light et al (21) and Egashira (22), although they, except for Egashira, examined COPD patients without oxygen therapy, and used different methods to assess depression [MMPI in (20), BDI in (21), SRQ$\mathrm{D}$ in (22)]. The significant correlation between HAD-A and HAD-D is also compatible with the report of Light et al (21) where the level of anxiety was assessed by TAI ( $r=0.81$, $\mathrm{p}<0.0001)$. They also found that there was a high prevalence of depression while anxiety was not prevalent. In contrast, Janson et al (23) reported that anxiety and depression measured by HAD scale were $30 \%$ and $8 \%$ in asthmatic patients. Thus it may be said that anxiety is more prevalent than depression in asthmatic patients and that the relationship is reciprocal in COPD patients without oxygen inhalation. When the disease becomes so severe and requires LTOT, patients may become more anxious about their physical deterioration, or about death. Borak et al (7) found that, of 48 patients with severe hypoxic COPD receiving or who had been accepted for LTOT, only four had no evidence of depression and only two had a "normal" level of anxiety. However, they used the Taylor Manifest Anxiety Scale (MAS) (24) and BDI for assessing anxiety and depression, and the mood disturbance may have been overestimated because of the influence of the physical impairment.

The result that $\mathrm{FEV}_{1.0}$ correlated remarkably with $\mathrm{PaCO}_{2}$ can be explained by the fact that ventilatory impairment is the main feature of COPD. The poor correlation between the physical state and anxiety or depression is consistent with other reports, and validates that the HAD scale is not influenced by physical impairment. Mahler et al (3) reported that the mood disturbance evaluated by MOS (Medical Outcome Study) survey (25) in patients with COPD was poorly correlated with $\mathrm{FEV}_{1.0}$ : Light et al (21) reported that neither depression nor anxiety correlated with $\mathrm{FEV}_{1.0}, \mathrm{PaO}_{2}$ or $\mathrm{PaCO}_{2}$. Thus, the independence of mood disturbance from the physical state may be common in COPD patients regardless of LTOT.

To quantify the intensity of sensations of dyspnea, the scale should have a ratio property: the measured value should be proportional to the actual amount perceived. Although the Borg Category Scale (26) has been widely used, its ratio property may be distorted by the epithet. In contrast, the VAS, which is also a category scale, has been reported to reflect the ratio property well (27). This scale has been used to measure the increase in dyspnea during exercise or hypercapnia (18), and is reported to have good reproducibility in the same subjects
(19).

A very high correlation between dyspnea and anxiety or depression is consistent with the report of Janson et al (23). Although their subjects were bronchial asthma patients, they reported that attacks of breathlessness both at rest and after activity correlated well with HAD. Mahler et al (3) also reported that dyspnea measured by BDTI and mental health score determined by MOS were correlated in patients with COPD. The results of the present study suggest that dyspnea perceived in daily life during LTOT is highly subject to mood disturbance.

The significant correlation between VAS and $\mathrm{FEV}_{1.0}$ in the present study was essentially the same as that found by Mahler et al (28), although they measured anxiety and depression with the MRC or BTDI. Campbell et al (29) proposed that dyspnea is derived from the length-tension or mechanical inappropriateness of the respiratory muscles. Gottfried et al (30) showed that the perception of changes in airflow resistance is impaired in patients with COPD. Burki (31) reported that breathless patients with chronic airway obstruction have a significantly increased inspiratory neuromuscular drive compared to those who are not breathless. Tobin (32) concluded that dyspnea results from the following factors: an increase in respiratory drive or effort necessary to overcome an imposed load, an increase in the proportion of respiratory muscle force required for breathing, and an increase in ventilatory requirements. An increase in ventilatory drive due to the flow limitation may be the main cause of this significant correlation, although the decrease in the efficiency of respiratory movement by the flattened diaphragm due to hyperinflation of the lung may play an important role in the results, because the majority of the subjects in the present study suffered to some degree from chronic pulmonary emphysema. However, the degree of correlation $(\mathrm{r}=0.32)$ was smaller than that found by Mahler et al (3) $(\mathrm{r}=0.70)$, who examined dyspnea by BDI in patients with COPD. This fact may be explained by the difference in the severity of the disease and the form of questionnaire. VAS in the present study asked about daily indoor life, where the influence of flow limitation may be less. The role in dyspnea of the third factor mentioned above is difficult to assess from the result that VAS in the present study did not correlate with $\mathrm{PaO}_{2}$ or $\mathrm{PaCO}_{2}$ because blood gas was sampled at rest with breathing air. Alanso et al (1) reported a poor correlation between dyspnea measured by American Society Dyspnea Criteria in COPD patients (33), but they examined non-oxygen-dependent COPD patients. The continuous monitoring of arterial blood gas during oxygen inhalation in daily life might result in a different correlation with VAS.

There are some discrepancies among the reports concerning the effect of oxygen therapy in COPD patients on mood disturbance or dyspnea. Heaton et al (34) studied patients from the Nocturnal Oxygen Therapy Trial (NOTT), and reported that there was no evidence that LTOT caused a reduction in mood disturbance such as depression or hysteria although there was a significant improvement in neuropsychological criteria such as motor ability or flexibility of thinking after six months of 
oxygen treatment. Lahdensuo et al (35) performed a similar analysis on patients with severe COPD before and after LTOT for six months, and found that depression was reduced after treatment to a level approaching significance $(\mathrm{p}<0.06)$, but the range of activities of daily life showed no change. In contrast, Dilworth et al (36) studied 30 patients with COPD who had recently been started on continuous oxygen therapy, and more than $80 \%$ reported considerable decrease in breathlessness. However, the present results indicate that one-third of the patients still suffered from anxiety or depression during LTOT. Taking into consideration the fact that dyspnea is influenced by mood disturbances, the quality of life may be improved by management of the psychological state. Borson et al (37) examined the impact of anti-depressant treatment on depression. They found that the treatment improved not only anxiety and depression, but also the health-related quality of life. Thus such treatment may also be effective for COPD patients during LTOT.

We conclude that in patients with COPD during LTOT, dyspnea is correlated with $\mathrm{FEV}_{1.0}$ and it is even more closely correlated with HAD-A and HAD-D. Considering that there is no correlation between FEV 1.0 and HAD-A or HAD-D, we speculate that mood disturbance and functional impairment contribute independently to sensations of dyspnea. The results indicate that more attention should be placed on the mental health care of COPD patients during LTOT.

Acknowledgements: We would like to thank A. Nakai, M.D., Ph.D. for introducing us to the psychological approach, and N. Sakai, M.D., Ph.D., Y. Takubo, M.D., T. Wakayama, M.D., H. Sekino, M.D., K. Kawakami, M.D., H. Kagioka, M.D., M. Hirabayashi, M.D., N. Harada, M.D., K. Kamakari, M.D., K. Muraishi, M.D. for clinical assistance. We also thank A.S. Zigmond, M.D. and M. Kitamura, M.D. for permission to use the HAD scale application.

\section{References}

1) Alanso J, Anto J, Gonzalez M, Fiz JA, Izoquierdo J, Morera J. Measurement of general state of non-oxygen dependent chronic obstructive pulmonary disease patients. Medical Care 30: 125, 1992.

2) Jones WJ, Baveystock CM, Littlejohns P. Relationships between general health measured with the sickness impact profile and respiratory symptoms, physiological measures, and mood in patients with chronic airflow limitation. Am Rev Respir Dis 140: 1538, 1989.

3) Mahler DA, Faryniarz, Tomlinson D. Impact of dyspnea and physiologic function on general health state in patients with chronic obstructive pulmonary disease. Chest 102: 395, 1992.

4) Belman MJ, Brroks LR, Ross DJ, Mohsenifer Z. Variability of breathlessness measurement in patients with chronic obstructive pulmonary disease. Chest 99: 566, 1991.

5) Burns BH, Howell JBL. Disproportionately severe breathlessness in chronic bronchitis. Q J Med 151: 277, 1969.

6) Curtis JR, Deyo RA, Hudson LD. Health-related quality of life among patients with chronic obstructive pulmonary disease. Thorax 49: 162, 1994.

7) Borak J, Sliwinski P, Piasecti Z, Zielinski J. Psychological effects of continuous oxygen therapy. Eur Respir J 4: 59, 1991.

8) Holman WJ, Medical Research Council. Committee on research into chronic bronchitis: instruction for use on the questionnaire on respiratory symptoms. Devon Press, New York, 1966.

9) Mahler MD, Weinberg DH, Wells CK, Freinstein AR. The measurement of dyspnea: contents, interobserver agreement, and physiologic corre- lated of two new clinical indexes. Chest 85: 751, 1984.

10) Dahlstrom WG, Welsh GS, Dahlstrom LE. An MMPI Handbook, revised edition. University of Minnesota Press, Minneapolis, 1972.

11) Jones PW, Quirk FH, Baveystock CM. A self-complete measure of health state for chronic airflow limitation. Am J Respir Dis 145: 1321, 1992.

12) Spielberger CD, Gorsuch RL, Luschene RE. STAI Manual. Consulting Psychologists Press, Palo Alto CA, 1970.

13) Beck AT, Ward CH, Mendelson M, Mock J, Erbaugh J. An inventory for measuring depression. Arch Gen Psychiat 4: 561, 1961.

14) Zigmond AS, Snaith RP. The hospital anxiety and depression scale. Acta Psychiatr Scand 67: 361, 1983.

15) Goodwin JF, Abdin ZH. The cardiogram of congenital and acquired right ventricular hypertrophy. Br Heart J 21: 523, 1959.

16) Miller MR, Gorecka DM, Bishop JM. Radiological prediction of pulmonary hypertension in chronic obstructive pulmonary disease. Eur Heart $\mathrm{J}$ 5: 581, 1984.

17) Kitamura M. Hospital anxiety and depression scale. Quarterly Psychiatric Diagnosis 4: 371, 1993.

18) Chonan T, Mulholland MB, Leitner J, Altose MD, Cheniack NS. Sensation of dyspnea during hypercapnia, exercise, and voluntary hyperventilation. J Appl Physiol 68: 2100, 1990.

19) Adams L, Chronos N, Lane R, Guz A. The measurement of breathlessness induced in normal subjects: validity of two scaling techniques. Clin Sci 69: 7, 1985.

20) McSweeny AJ, Grant I, Adams KM, Timms RM. Life quality of patients with chronic obstructive pulmonary disease. Arch Intern Med 142: 473, 1982.

21) Light RW, Merrill EJ, Despars JA, Gordon GH, Mutalipassi LR. Prevalence of depression and anxiety in patients with COPD. Chest 87: 35, 1985.

22) Egashira Y. Psychological approach to chronic respiratory failure (in Japanese). Nippon Kyobu-Shikkan-Gakkai-Zasshi 30: 1483, 1992.

23) Janson C, Bjornsson E, Hetta J, Boman G. Anxiety and depression in relation to respiratory symptoms and asthma. Am J Respir Crit Care Med 149: 930, 1994.

24) Taylor JA. A personality scale or manifest anxiety. in: Personality Research, Medical Press, New Jersey, 1966.

25) Stewart AL, Hays RD, Ware JE. The MOS short-form general survey: reliability and validity in a patient population. Med Care 26: 726, 1988.

26) Borg G. Psychological basis of perceived exertion. Med Sci Sports Exerc 14: $377,1982$.

27) price DD, McGrath PA, Rafii A, Buckingham B. The validation of visual analog scales as ratio scale measures for chronic and experimental pain. Brain Res Bull 17: 45, 1983.

28) MahlerDA, Rosiello A, Harver A, Lentine T, McGovern JF, Daubenspeck JA. Comparison of clinical dyspnea ratings and psychophysical measurements of respiratory sensation in obstructive airway disease. Am Rev Respir Dis 135: 1229, 1987.

29) Campbell EJM, Freedman S, Smith PS, Taylor ME. The ability of man to detect added elastic loads to breathing. Clin Sci 20: 223, 1961.

30) Gottfried SB, Altose MD, Kelsen SG, Cherniack NS. Perception of changes in airflow resistance in obstructive pulmonary disorders. Am Rev Respir Dis 124: 566, 1981.

31) Burki NK. Breathlessness and mouth occlusion pressure in patients with chronic obstruction of the airways. Chest 76: 527, 1979.

32) Tobin MJ. Dyspnea, pathologic basis, clinical presentation and management. Arch Intern Med 1604, 1990.

33) Mahler DA. Dyspnea: diagnosis and management. Clin Chest Med 8: 215, 1987.

34) Heaton RK, Grant I, McSweeny AJ, Adams KM, Petty TL. Psychologic effects of continuous and nocturnal oxygen therapy in hypoxic chronic obstructive pulmonary disease. Arch Intern Med 143: 1941, 1983.

35) Lahdensuo A, Ojanen M, Ahonen A, Pappiu J, Salorinne Y, Tammiuaara R. Psychological effects of continuous oxygen therapy in hypoxemic chronic obstructive pulmonary disease. Eur Respir J 2: 977, 1989.

36) Dilworth JP, Higgs CMB, Jones PA, White RJ. Acceptability of oxygen concentrations: The patient's view. Br J Gen Pract 40: 415, 1990. 


\section{Mishima et al}

37) Borson S, McDonald GJ, Gayle T, Deffebach M, Lakshminarayan S, van Tuinen C. Improvement in mood, physical symptoms, and function with nortriptyline for depression in patients with chronic pulmonary obstructive disease. Psychosomatics 33: 190, 1992. 